\title{
HPLC-MS/MS Profiling of Wild-growing Scentless Chamomile
}

\author{
Filip Šibul ${ }^{1^{*}}$, Dejan Orčić ${ }^{1}$, Sanja Berežni ${ }^{1}$, Goran Anačkov ${ }^{2}$ and Neda Mimica-Dukić ${ }^{1}$ \\ ${ }^{\prime}$ Department of Chemistry, Biochemistry and Environmental Protection, Faculty of Sciences, University of Novi Sad, Trg Dositeja \\ Obradovića 3, 21000 Novi Sad, Serbia \\ 2Department of Biology and Ecology, Faculty of Sciences, University of Novi Sad, Trg Dositeja Obradovića 3, 21000 Novi Sad, Serbia
}

Received: 13 September 2018; accepted: 22 January 2019

\begin{abstract}
Scentless chamomile (Tripleurospermum inodorum $=M$. inodora) is a plant belonging to Anthemideae tribe of Asteraceae family, with phenotype similar to the common chamomile, a plant used in human consumption in the form of herbal tea infusion. In order to be able to understand possible health-promoting properties and adverse effects of the scentless chamomile's consumption, it is of essence to examine its chemical composition. The aim of the study was to perform phenolic profiling using high-performance liquid chromatography-tandem mass spectroscopy (HPLC-MS/MS), in comparison to the common chamomile. In the investigated extracts, qualitative and quantitative analyses enabled the identification of 66 compounds based on their retention times, mass (MS/MS) spectra, and analysis of their characteristic fragmentation patterns in MS/MS Product Ion Scan experiments. A new HPLCMS/MS method for quantitation of common plant metabolites was hereby developed, enabling quantitation of 47 compounds. All examined $M$. inodora samples have relatively high combined phenolic and flavonoid contents $(25.2-51.9 \mathrm{mg} / \mathrm{g})$. Apigenin, apigenin-7-O-glucoside, luteolin, luteolin-7-O-glucoside, quinic acid, and 5-O-caffeoyl quinic acid were the compounds with highest concentration in both inodorous and common chamomile. The results obtained hereby represent the first and most detailed chemical profile of scentless chamomile so far.
\end{abstract}

Keywords: flavonoids, scentless mayweed, wild chamomile, false chamomile, false mayweed

\section{Introduction}

Phenolic compounds and flavonoids are secondary plant metabolites which have a wide variety of potentially positive effects on human health $[1,2]$. Because of its specific phenolic and flavonoid content, the common chamomile (Matricaria chamomilla L. 1753, syn. M. recutita L., Chamomilla recutita (L.) Rauschert) is widely used as food supplement and herbal tea [3], as well as in cosmetic products [4]. Chamomile is a rich source of flavonoids and other biologically active compounds in both its essential oil and extract, having anti-inflammatory, antibacterial, anti-allergic, antioxidant [5], diuretic, sedative, and carminative activity and being used externally for the treatment of skin wounds, mouth sores, and hemorrhoids, reducing inflammation and inhibiting gastric ulcers [6] and development of carcinogenic cells [2, 4, 7-9]. In addition to the medicinal uses, its essential oil is extensively used in food industry, as well as in parfumery, cosmetics, and aromatherapy to serve as emollient and to maintain the stability or potency of the formulations $[4,10,11]$.

Tripleurospermum inodorum (L.) Schultz Bip. is an annual herb from the Asteraceae family, also recognized as $M$. inodora L., C. inodora (L.) Gilib, M. maritima var. agrestis (Knaf) Wilmott, M. maritima auct. p.p. non L., M. maritima ssp. inodora (K. Koch) Soó, M. maritima ssp. inodora (L.) Clapham, M. perforata Mèrat (Rauschert 1974), T. perforatum (Mèrat) Wagenitz, T. maritimum (L.) Schultz Bip. p.p. non L., and T. maritimum ssp. inodorum (L.) N. Hylander ex Voor $[7,12,13]$. Its common name is scentless chamomile, but it

*Author for correspondence: E-mail: filip.sibul@dh.uns.ac.rs; Tel.: +381-21485-2765. is also known as scentless mayweed, barnyard daisy, corn feverfew, wild chamomile, false chamomile, false mayweed, or bachelor's button [13]. In Nordic countries, scentless mayweed is also called Balder's brae, an ancient plant name used to describe $T$. inodorum [14]. It is commonly found throughout the lowlands of Europe, on cultivated land, waste places, and saline steppes, similar to the common scented chamomile [15]. The two species often occur at similar sites and can therefore be collected together for chamomile herbal tea by mistake, due to their similar phenotypes. However, the knowledge about the chemistry and medicinal uses of $T$. inodorum, in comparison to chamomile is limited. Namely, in contrast to chamomile's therapeutic effects, there are only minor reports of the scentless chamomile's health-promoting properties, since it is not traditionally used and is considered weed [12, 13, 16, 17]. Nevertheless, $80 \%$ methanolic extract of $M$. inodora was found to be effective against urease activity $\left(\mathrm{IC}_{50}=100.6 \mu \mathrm{g} / \mathrm{mL}\right)$ and it was reported to contain compounds that act as carminatives, relieving gastrointestinal pain, and flavonoids, which contribute to its anti-inflammatory activity [18]. These effects are probably responsible for its reported use to relieve indigestion and promote appetite and for the treatment of stomach ulcers, helping prevent food poisoning and treat gastric ulcer and swollen liver and spleen [18]. It was also used in the prehistoric dyeing methods, in which apigenin is considered responsible for its yellow color [19].

Due to the limited knowledge about the composition of this plant, in order to utilize it for its possible health-promoting properties, its chemical profiling should be the first step. This work was therefore necessary, and the performed study is important for explaining and understanding the plant's potential.

This is an open-access article distributed under the terms of the Creative Commons Attribution-NonCommercial 4.0 International License (https://creativecommons.org/licenses/by-nc/4.0/), which permits unrestricted use, distribution, and reproduction in any medium for non-commercial purposes, provided the original author and source are credited, a link to the CC License is provided, and changes - if any - are indicated. 
Moreover, from a chemotaxonomic point of view, it is interesting to compare the chemical composition, i.e., phenolic profiling of wild growing scented [20] and scentless chamomile, since they could cause confusion among the herb collectors and end up together, leading to adulteration in tea infusion [21, 22].

The common instrumentation for phenolic profiling, i.e., detection and quantification of phenolic compounds comprise of high-performance liquid chromatography (HPLC) coupled with UV/Vis detection (diode-array detector [DAD]) [23, 24] and mass spectrometric detector (MS) [1, 4, 20, 25, 26]. High-performance thin-layer chromatography (HPTLC) [21, 22, 27, 28], and capillary electrochromatography $[10,29]$ could be used alternatively. A HPLC-triple quadrupole tandem mass spectrometer (HPLC-QQQ-MS/MS) system is the preferred option for quality assessment $[30,31]$, i.e., quantitative analysis of phenolic compounds in plant extracts [24, 32-34]. Therefore, the authors have chosen to use liquid chromatography coupled to a triple quadrupole tandem mass spectrometry for the chemical profiling of the extracts, and developed a new quantitation method.

\section{Experimental}

Standards and Reagents. Deionized water was produced using Elga LabWater Purelab Option-Q water purification system. HPLC gradient grade methanol and reagent grade (p.a.) methanol were purchased from J.T. Baker (Deventer, The Netherlands), and p.a. formic acid and DMSO from Merck (Darmstadt, Germany). Reference compounds used in quantitative study were obtained from Sigma-Aldrich Chem (Steinheim, Germany), Fluka Chemie GmbH (Buchs, Switzerland) and from Chromadex (Santa Ana, USA) [35]. Reference compounds in the standard mix of 45 compounds: $p$-hydroxybenzoic acid, cinnamic acid, protocatechuic acid, gentisic acid, umbeliferone, $p$-coumaric acid, $o$-coumaric acid, vanillic acid, gallic acid, esculetin, caffeic acid, quinic acid, scopoletin, ferulic acid, syringic acid, 3,4-dimethoxycinnamic acid, sinapic acid, daidzein, apigenin, genistein, baicalein, naringenin, luteolin, kaempferol, catechin, epicatechin, chrysoeriol, quercetin, isorhamnetin, myricetin, 5-Ocaffeoylquinic acid, matairesinol, secoisolariciresinol, apigenin 7-O-glucoside, vitexin, baicalein, kaempferol 3-O-glucoside, luteolin 7-O-glucoside, quercetin, epigallocatechin gallate, hyperoside, quercetin 3-O-glucoside, amentoflavone, apiin, and rutin. Reference compounds in the standard mix of 25 compounds: pinocembrin, pinostrobin, hesperetin, liquiritigenin, naringin, chrysin, galangin, morin, rhamnetin, diosmetin, dantron, alizarin, rhein, emodin, aloe-emodin, cis, trans-abscisic acid, isoliquiritigenin, ellagic acid, glycyrrhizin, $18 \beta$-glycyrrhetinic acid, 4-hydroxyphenylacetic acid, formononetin, isoscopoletin, ursolic acid, and resveratrol.

Plant Material and Extracts Preparation. Plant material used for the analysis was collected during summer of 2015 in Vojvodina region (Serbia) - southern part of Pannonian Basin, north of the Danube river. The plant material was identified by Prof. Dr. Goran Anačkov, and the voucher specimens are deposited in the Herbarium of Department of Biology and Ecology (BUNS Herbarium), University of Novi Sad Faculty of Sciences. The only exception is the M. chamomilla material, a commercial sample bought from a local store in Novi Sad (Serbia) in form of dry chamomile flowers. The fresh plant material was air-dried at room temperature, and the dried flowers were powdered afterwards, in order to perform extraction. The extraction of secondary metabolites was performed according to the previously developed method by Šibul et al. (2016) [36]. Maceration with $13 \mathrm{~mL}$ of $80 \%$
Table 1. Optimized dynamic SRM parameters for quantification of the 25 standard compounds

\begin{tabular}{lccccc}
\hline Compound & \multicolumn{3}{l}{ Precursor } & Product & \multicolumn{2}{l}{$V_{\text {fragmentor }}$} & \multicolumn{2}{l}{$V_{\text {collision }} t_{\mathrm{R}}$} \\
\cline { 2 - 7 } & $m / z$ & $m / z$ & $(\mathrm{~V})$ & $(\mathrm{V})$ & $(\mathrm{min})$ \\
\hline 4-Hydroxyphenylacetic acid & 151 & 107 & 80 & 10 & 1.07 \\
Isoscopoletin & 191 & 176 & 120 & 5 & 1.5 \\
Resveratrol & 227 & 185 & 130 & 15 & 2.26 \\
Alizarin & 239 & 210 & 190 & 30 & 5.49 \\
Dantron & 239 & 211 & 200 & 25 & 7.54 \\
Chrysin & 253 & 143 & 150 & 23 & 6.04 \\
Pinocembrin & 255 & 213 & 130 & 18 & 5.71 \\
Liquiritigenin & 255 & 119 & 100 & 22 & 2.95 \\
Isoliquiritigenin & 255 & 119 & 100 & 22 & 4.57 \\
Cis, trans-abscisic acid & 263 & 153 & 170 & 0 & 3.48 \\
Formononetin & 267 & 252 & 100 & 16 & 5.2 \\
Aloe-emodin & 269 & 240 & 170 & 19 & 5.83 \\
Emodin & 269 & 225 & 160 & 25 & 7.77 \\
Pinostrobin & 269 & 269 & 130 & 0 & 6.31 \\
Galangin & 269 & 169 & 150 & 23 & 6.3 \\
Rhein & 283 & 239 & 90 & 10 & 6.5 \\
Diosmetin & 299 & 284 & 140 & 20 & 4.69 \\
Hesperetin & 301 & 164 & 125 & 23 & 4.11 \\
Morin & 301 & 149 & 120 & 29 & 2.92 \\
Ellagic acid & 301 & 301 & 152 & 0 & 2.23 \\
Rhamnetin & 315 & 165 & 140 & 19 & 5.4 \\
Ursolic acid & 455 & 455 & 300 & 12 & 9.44 \\
18ß-Glycyrrhetinic acid & 469 & 425 & 280 & 40 & 8.89 \\
Naringin & 579 & 271 & 230 & 35 & 2.25 \\
Glycyrrhizin & 821 & 351 & 220 & 45 & 6.98 \\
\hline & & & & &
\end{tabular}

aqueous methanol per $1 \mathrm{~g}$ of dry plant material was performed for $90 \mathrm{~min}$, with constant shaking at room temperature. The plant material was removed after each extraction portion by filtration, using the MF-Millipore ${ }^{\mathrm{TM}} 0.45 \mu \mathrm{m}$ mixed cellulose ester membrane filters, and the raw extract was evaporated under a nitrogen flow. Each of the obtained dry extracts was reconstituted in DMSO to achieve final concentration of $200 \mathrm{mg} / \mathrm{mL}$, for their storage [34].

Quantitative HPLC-MS/MS Analysis. For quantitative determination of compounds in the examined extracts, the method for quantification of 45 plant phenolics by Orčić et al., 2014 [33] was used, and a new method for quantification of 25 additional compounds commonly occurring in plants was developed and hereby introduced. Prior to the analysis, all extracts were diluted in a mixture of water and methanol premixed in a 1:1 ratio, to obtain a final concentration of $2 \mathrm{mg} / \mathrm{mL}$. For each of the two standard mixes, 15 working standards, with concentrations of each compound ranging from 1.53 to $25,000 \mathrm{ng} / \mathrm{mL}$, were prepared by serial $1: 1$ dilutions in the water-methanol mixture $(1: 1)$. All samples and standards were analyzed using Agilent Technologies 1200 Series high-performance liquid chromatograph coupled with Agilent Technologies 6410A Triple Quad (QQQ) tandem mass spectrometer with an electrospray (ESI) ion source and controlled by Agilent Technologies MassHunter Workstation software - Data Acquisition (ver. B.03.01). Five microliters were injected into the system, and the compounds were separated on Zorbax Eclipse XDB-C18 (50 mm $\times 4.6 \mathrm{~mm}, 1.8 \mu \mathrm{m})$ reversed-phase rapid resolution column held at $50{ }^{\circ} \mathrm{C}$. The mobile phase consisted of $0.05 \%$ aqueous formic acid (A) and methanol (B) and was delivered at flow rate of $1 \mathrm{~mL} / \mathrm{min}$ in the optimized gradient eluting mode $(0 \min 30 \% \mathrm{~B}, 6 \min 70 \% \mathrm{~B}, 9 \mathrm{~min}$ $100 \% \mathrm{~B}, 12 \mathrm{~min} 100 \% \mathrm{~B}$, re-equilibration time $3 \mathrm{~min}$ ). Eluting compounds were detected by the aforementioned ESItandem mass spectrometer, using the ion source parameters as follows: a nebulization gas $\left(\mathrm{N}_{2}\right)$ pressure of $50 \mathrm{psi}$, a drying gas $\left(\mathrm{N}_{2}\right)$ flow of $10 \mathrm{~L} / \mathrm{min}$, a temperature of $350{ }^{\circ} \mathrm{C}$, and a capillary voltage of $4 \mathrm{kV}$, in the negative mode (negative polarity, NI). Data were acquired in the dynamic selected reaction monitoring $(\mathrm{SRM})$ mode, after the optimization of the 
compound-specific parameters for each of the standards used for quantification - retention time $\left(t_{\mathrm{R}}\right)$, precursor ion, product ion, fragmentor voltage $\left(V_{\text {fragmentor }}\right)$, and collision voltage $\left(V_{\text {collision }}\right)-$ given in Table 1. For all detected compounds, peak areas were determined using Agilent MassHunter Workstation software - Qualitative Analysis (ver. B.03.01.). Calibration curves were plotted and samples' concentrations were calculated using the OriginLab Origin Pro (ver. 9.0) software.

Qualitative HPLC-MS/MS Analysis. For qualitative analysis, the extracts were diluted in a mixture of water and methanol (1:1), to obtain a final concentration of $25 \mathrm{mg} / \mathrm{mL}$. The samples were analyzed using an Agilent Technologies 1200 Series HPLC coupled with an Agilent Technologies 6410A Triple Quad ESI-MS/MS, as well. Five microliters were injected into the system, and the compounds were separated on a Zorbax Eclipse XDB-C18 $(50 \mathrm{~mm} \times 4.6 \mathrm{~mm}$, $1.8 \mu \mathrm{m})$ rapid resolution column held at $50{ }^{\circ} \mathrm{C}$. The mobile phase (A: $0.05 \%$ aqueous formic acid; B: methanol) was delivered at a flow rate of $0.5 \mathrm{~mL} / \mathrm{min}$ in the gradient mode (0 min 30\% B, 10 min 70\% B, 15 min 100\% B, 20 min 100\% $\mathrm{B}$, re-equilibration time $4 \mathrm{~min}$ ). ESI-MS ion source parameters were the same as the above-mentioned parameters for quantitative analysis. Full scan mode (MS2Scan: $\mathrm{m} / \mathrm{z}$ range $35-800$, scan time $100 \mathrm{~ms}$, fragmentor voltage $135 \mathrm{~V}$ ), using both polarities, was used to detect the compounds present in the extract samples, determine their molecular weight, and select the precursor ions for $\mathrm{MS}^{2}$ experiments. To obtain structural information and identify the detected compounds, Product Ion Scan analysis ( $\mathrm{MS}^{2}$ experiment) was performed, with protonated $\left([\mathrm{M}+\mathrm{H}]^{+}\right)$and deprotonated $\left([\mathrm{M}-\mathrm{H}]^{-}\right)$ molecular ions as precursors and collision voltages in 10-40 V interval (with $10 \mathrm{~V}$ increments). The compounds were identified according to the corresponding spectral characteristics: mass (MS/MS) spectra, characteristic fragmentation pattern, and retention time.

\section{Results and Discussion}

Method Development for Quantification of 25 Plant Secondary Metabolites. Twenty-five reference compounds [35] were chosen to be included into the method for quantification of common plant secondary metabolites, based on their occurrence in plants and availability of the reference compounds: 10 flavonoids (pinocembrin, pinostrobin, hesperetin, liquiritigenin, naringin, chrysin, galangin, morin, rhamnetin, and diosmetin), 5 anthraquinones (dantron, alizarin, rhein, emodin, and aloe-emodin), cis, trans-abscisic acid, isoliquiritigenin, ellagic acid, glycyrrhizin, $18 \beta$ glycyrrhetinic acid, 4-hydroxyphenylacetic acid, formononetin, isoscopoletin, ursolic acid, and resveratrol. HPLC method for separation and detection of the aforementioned compounds was previously developed for the separation of extract components and quantification of 45 compounds by Orčić et al. (2014) [33]. The injection volume was set to $5 \mu \mathrm{L}$ in order to provide the maximum sensitivity. The mobile phase composition enables both the adequate ionization (with the use of $0.05 \%$ formic acid) and satisfactory chromatographic performance (retention and peak shape). For the detection of the compounds eluting from Zorbax Eclipse XDB-C18 reversed-phase column, an electrospray ionization triple-quad tandem mass spectrometer was used, firstly in MS2Scan mode (negative polarity, NI) in order to locate peaks and choose precursor ions for each of the 25 compounds. High yield of $[\mathrm{M}-\mathrm{H}]^{-}$ions was achieved by optimization of fragmentor voltage $\left(V_{\text {fragmentor }}\right)$ for each compound. For this purpose, the standard mix of the 25
Table 2. Validation results - linear fit parameters, repeatability standard deviation $\left(r \mathrm{~s}_{\mathrm{r}}\right)$, limit of quantitation (LoQ), and limit of detection (LoD)

\begin{tabular}{|c|c|c|c|c|c|c|c|}
\hline \multirow[t]{2}{*}{ Compound } & \multicolumn{2}{|c|}{ Linear fit } & \multicolumn{3}{|c|}{ In solvent } & \multicolumn{2}{|c|}{ In matrix } \\
\hline & $r^{2}$ & $\begin{array}{l}\operatorname{Limit}^{a} \\
(\mu \mathrm{g} / \mathrm{mL})\end{array}$ & $\begin{array}{l}r \mathrm{~s}_{\mathrm{r}}^{c} \\
(\%)\end{array}$ & $\begin{array}{l}L o D \\
(\mu \mathrm{g} / \\
\mathrm{mL})\end{array}$ & $\begin{array}{l}\mathrm{LoQ} \\
(\mu \mathrm{g} / \\
\mathrm{mL})\end{array}$ & $\begin{array}{l}L o D \\
(\mu \mathrm{g} / \\
\mathrm{mL})\end{array}$ & $\begin{array}{l}\mathrm{LoQ} \\
(\mu \mathrm{g} / \\
\mathrm{mL})\end{array}$ \\
\hline \multicolumn{8}{|l|}{$\overline{4-}$} \\
\hline $\begin{array}{l}\text { Hydroxyphenylacetic } \\
\text { acid }\end{array}$ & 0.998 & $25^{b}$ & 6 & 0.05 & 0.05 & 0.02 & 0.05 \\
\hline Isoscopoletin & 0.993 & $25^{b}$ & 2 & 0.006 & 0.006 & 0.003 & 0.003 \\
\hline Resveratrol & 0.994 & 6.2 & 4 & 0.02 & 0.04 & 0.01 & 0.01 \\
\hline Alizarin & 0.984 & $25^{b}$ & $\mathrm{n} / \mathrm{a}^{d}$ & 0.1 & 0.1 & 0.01 & 0.01 \\
\hline Dantron & 0.988 & 12 & $\mathrm{n} / \mathrm{a}^{d}$ & 0.1 & 0.1 & 0.05 & 0.08 \\
\hline Chrysin & 0.996 & 3.1 & 5 & 0.006 & 0.01 & 0.003 & 0.006 \\
\hline Pinocembrin & 0.994 & 3.1 & 3 & 0.006 & 0.01 & 0.003 & 0.003 \\
\hline Liquiritigenin & 0.999 & 0.78 & 1 & 0.003 & 0.003 & 0.003 & 0.003 \\
\hline Isoliquiritigenin & 0.999 & 6.2 & 2 & 0.003 & 0.004 & 0.003 & 0.003 \\
\hline $\begin{array}{l}\text { Cis,trans-abscisic } \\
\text { acid }\end{array}$ & 0.995 & $25^{b}$ & 8 & 0.02 & 0.03 & 0.003 & 0.006 \\
\hline Formononetin & 0.991 & 3.1 & 2 & 0.003 & 0.003 & 0.003 & 0.003 \\
\hline Aloe-emodin & 0.996 & 12 & 9 & 0.02 & 0.08 & 0.01 & 0.01 \\
\hline Emodin & 0.993 & 3.1 & 3 & 0.006 & 0.008 & 0.003 & 0.003 \\
\hline Pinostrobin & 0.998 & 3.1 & 2 & 0.003 & 0.005 & 0.003 & 0.003 \\
\hline Galangin & 0.998 & 3.1 & 11 & 0.02 & 0.08 & 0.01 & 0.01 \\
\hline Rhein & 0.992 & 6.2 & 5 & 0.006 & 0.02 & 0.003 & 0.003 \\
\hline Diosmetin & 0.994 & 3.1 & 2 & 0.003 & 0.003 & 0.003 & 0.006 \\
\hline Hesperetin & 0.993 & 6.2 & 3 & 0.006 & 0.01 & 0.003 & 0.006 \\
\hline Morin & 0.999 & $25^{b}$ & 8 & 0.05 & 0.05 & 0.05 & 0.05 \\
\hline Ellagic acid & 0.982 & 1.6 & 7 & 0.1 & 0.1 & 0.1 & 0.1 \\
\hline Rhamnetin & 0.983 & $25^{b}$ & $\mathrm{n} / \mathrm{a}^{d}$ & 0.1 & 0.1 & 0.003 & 0.003 \\
\hline Ursolic acid & 0.996 & 3.1 & 3 & 0.003 & 0.007 & 0.003 & 0.003 \\
\hline $\begin{array}{l}18 \beta \text {-Glycyrrhetinic } \\
\text { acid }\end{array}$ & 0.997 & 6.2 & 9 & 0.02 & 0.03 & 0.006 & 0.006 \\
\hline Naringin & 0.999 & $25^{b}$ & 4 & 0.006 & 0.02 & 0.003 & 0.003 \\
\hline Glycyrrhizin & 0.996 & $25^{b}$ & 14 & 0.01 & 0.02 & 0.01 & 0.01 \\
\hline
\end{tabular}

${ }^{a}$ Linearity limit - the highest calibration level used for linear regression.

${ }^{b}$ The highest concentration tested - actual limit may be higher.

${ }^{c}$ Relative standard deviation of repeatability determined at $98 \mathrm{ng} / \mathrm{mL}$. ${ }^{d}$ Signal too weak at $98 \mathrm{ng} / \mathrm{mL}$ level.

compounds was analyzed in MS2SIM mode, using fragmentor voltages in range of $140-260 \mathrm{~V}$, in $10 \mathrm{~V}$ increments. Peak areas were plotted vs. fragmentor voltage, and the optimal $V_{\text {fragmentor }}$ were read from the curves. The standard mixture was subsequently analyzed in Product Ion (PI) Scan mode, using $[\mathrm{M}-\mathrm{H}]^{-}$ions as precursors and optimal $V_{\text {fragmentor }}$ and collision cell voltages $\left(V_{\text {collision }}\right)$ ranging from $10-40 \mathrm{~V}$, in $10 \mathrm{~V}$ increments. The obtained $\mathrm{MS}^{2}$ spectra were used to select the optimal product ions - abundant fragments, preferably produced by less common neutral losses, specific for each compound. However, 3 of the abovementioned compounds - pinostrobin, ellagic acid, and ursolic acid exhibited poor fragmentation; therefore, $[\mathrm{M}-\mathrm{H}]^{-}$was chosen as the target ion for each of them, since using any of the fragments obtained at higher collision voltages would significantly decrease detection sensitivity. Finally, the standard mixture was analyzed in SRM (selected reaction monitoring) mode using $V_{\text {collision }}$ in the range of $0-50 \mathrm{~V}$, in $10 \mathrm{~V}$ increments. Peak areas were plotted vs. collision voltage, in order to find the optimal $V_{\text {collision }}$ for each of the compounds. An acquisition method was then set by using the optimized parameters. Due to a large number of close-eluting peaks, the dynamic SRM mode was used for quantification, monitoring each transition in $1 \mathrm{~min}$ interval around the expected retention time of each compound. The optimized compound-specific parameters for dynamic SRM (retention time, precursor ion, product ion, fragmentor voltage, and collision voltage) are given in Table 1.

Method Validation for Quantification of 25 Plant Secondary Metabolites. Retention times $\left(t_{\mathrm{R}}\right)$ showed good repeatability, with standard deviations (as determined from calibration standards) not greater than 0.004 min for standards 
Table 3. Chromatographic and mass spectrometric identification of the detected compounds

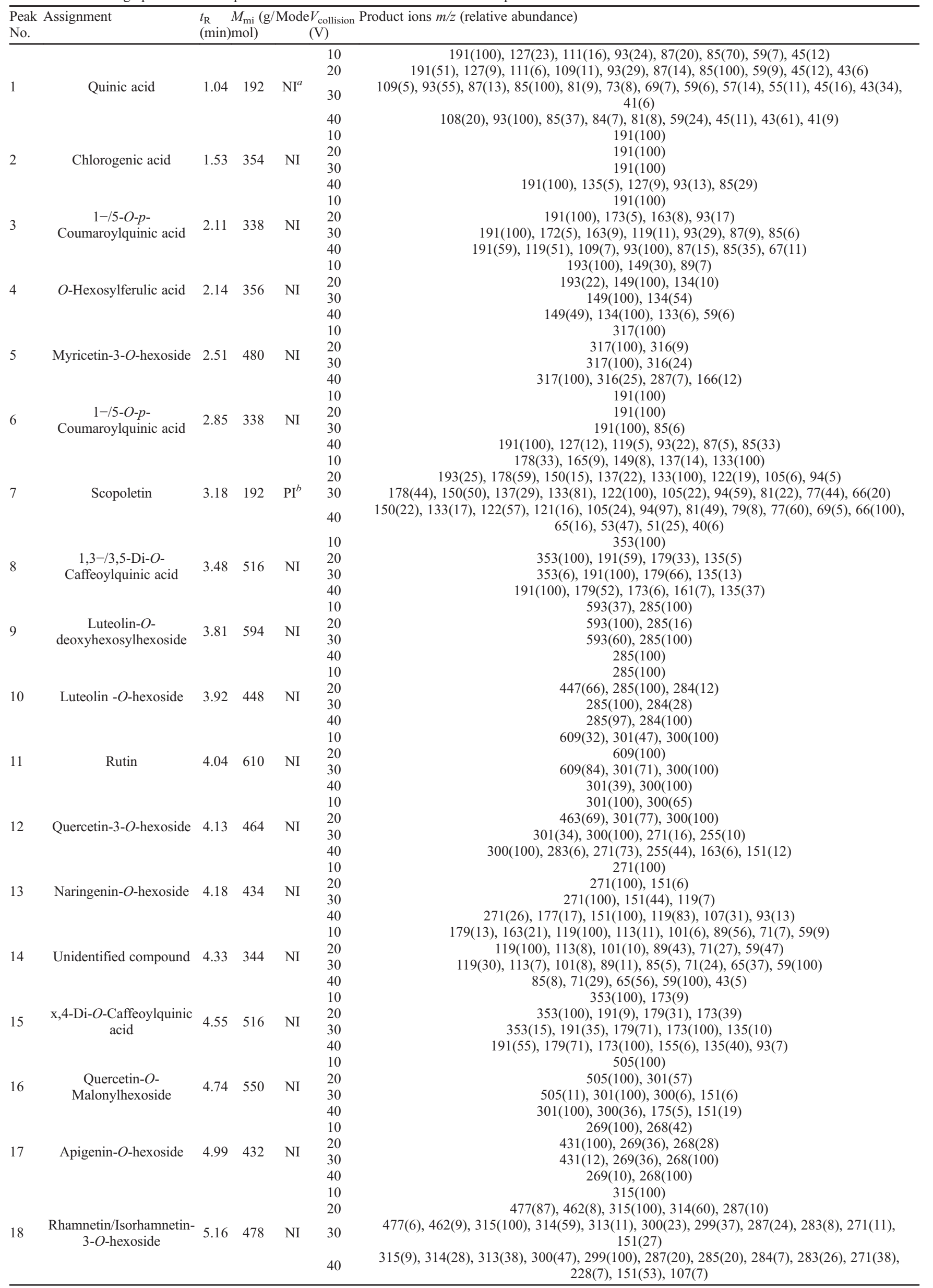


Table 3. (contd.)

\begin{tabular}{|c|c|c|c|c|c|c|}
\hline \multirow[t]{2}{*}{$\begin{array}{l}\text { Peak } \\
\text { No. }\end{array}$} & \multirow[t]{2}{*}{ Assignment } & \multicolumn{5}{|c|}{$\begin{array}{l}t_{\mathrm{R}} M_{\mathrm{mi}}\left(\mathrm{g} / \mathrm{Mode} V_{\text {collision }} \text { Product ions } m / z \text { (relative abundance) }\right. \\
\begin{array}{ll}(\mathrm{min}) \mathrm{mol}) & (\mathrm{V})\end{array}\end{array}$} \\
\hline & & & & & 10 & $489(100)$ \\
\hline \multirow{4}{*}{19} & Luteolin/Kaempferol-O- & & & & 20 & 489(100), 285(24) \\
\hline & malonylhexoside & 5.32 & 534 & $\mathrm{~N} 1$ & 30 & $489(39), 285(100), 284(13)$ \\
\hline & & & & & 40 & $285(100), 284(54)$ \\
\hline & & & & & 10 & $477(100)$ \\
\hline \multirow{4}{*}{20} & Rhamnetin/Isorhamnetin- & -5.49 & 478 & $\mathrm{NI}$ & 20 & $477(100), 315(18), 314(44)$ \\
\hline & 3-O-hexoside & 5.49 & $4 / 8$ & $\mathrm{NI}$ & 30 & $315(5), 314(100), 299(16), 285(10), 271(8), 270(6), 243(5)$ \\
\hline & & & & & 40 & $314(82), 299(27), 286(14), 285(62), 271(100), 257(8), 243(49)$ \\
\hline & & & & & 10 & $325(12), 315(100), 314(7)$ \\
\hline \multirow{4}{*}{21} & Rhamnetin/Isorhamnetin- & & & NI & 20 & $519(26), 315(100), 314(31)$ \\
\hline & $O$-acetylhexoside & 6.00 & 520 & $\mathrm{~N} 1$ & 30 & $315(81), 314(100), 300(17), 299(58), 161(7)$ \\
\hline & & & & & 40 & $315(26), 314(43), 300(35), 299(100), 271(28), 243(7)$ \\
\hline & & & & & 10 & $269(100), 268(72)$ \\
\hline \multirow{4}{*}{22} & Apigenin- $O$ - & 6.32 & 474 & $\mathrm{NI}$ & 20 & $473(100), 269(25), 268(27)$ \\
\hline & acetylhexoside & 0.32 & $4 / 4$ & $\mathrm{NI}$ & 30 & $473(23), 269(47), 268(100)$ \\
\hline & & & & & 40 & $269(23), 268(100)$ \\
\hline & & & & & 10 & $605(100)$ \\
\hline \multirow{5}{*}{23} & & & & & 20 & $605(100)$ \\
\hline & Unidentified compound & 6.55 & 606 & NI & 30 & $605(100)$ \\
\hline & & & & & 40 & $605(100)$ \\
\hline & & & & & 10 & 273(10), 257(6), 179(100), 151(86), 107(6) \\
\hline & & & & & 20 & $301(43), 273(15), 179(49), 151(100), 121(22), 107(12)$ \\
\hline \multirow[t]{3}{*}{24} & Quercetin & 6.91 & 302 & NI & 30 & 179(11), 151(100), 121(47), 107(58), 93(8), 83(15), 65(14), 63(12) \\
\hline & & & & & 40 & $\begin{array}{c}227(6), 199(6), 187(6), 182(10), 164(7), 163(8), 161(12), 159(6), 151(99), 149(10), 121(91), \\
109(15), 108(14), 107(89), 93(57), 89(6), 83(81), 65(100), 63(71)\end{array}$ \\
\hline & & & & & 10 & $271(6), 177(22), 165(5), 151(100), 119(27), 107(12), 93(8)$ \\
\hline \multirow{4}{*}{25} & Naringenin & 730 & 272 & NI & 20 & $271(23), 177(14), 151(100), 119(92), 107(30), 93(12), 83(7), 65(6)$ \\
\hline & Naringenin & 1.30 & $2 / 2$ & $\mathrm{NI}$ & 30 & $151(12), 119(100), 107(22), 93(7), 83(16), 65(13), 63(11)$ \\
\hline & & & & & 40 & $119(100), 107(5), 93(9), 83(11), 65(20), 63(9)$ \\
\hline & & & & & 10 & $285(100), 199(6), 151(6), 133(14)$ \\
\hline \multirow{4}{*}{26} & & & & & 20 & $285(100), 133(6)$ \\
\hline & Luteolin & 7.45 & 286 & $\mathrm{NI}$ & 30 & $285(51), 241(6), 217(8), 201(8), 199(13), 175(19), 151(29), 149(11), 133(100), 107(16), 65(6)$ \\
\hline & & & & & 40 & $175(6), 133(100), 132(10), 107(11), 65(9)$ \\
\hline & & & & & 10 & $697(100)$ \\
\hline \multirow{4}{*}{27} & Unidentified comnound & 770 & 742 & NI & 20 & 697(100), 365(20), 331(60) \\
\hline & Unidentified compound & 7.70 & 742 & NI & 30 & $697(15), 365(30), 331(100), 209(8)$ \\
\hline & & & & & 40 & $365(10), 331(100), 316(18), 179(16), 161(18)$ \\
\hline & & & & & 10 & $269(100), 268(64)$ \\
\hline \multirow{5}{*}{28} & Apigenin- $O-$ & 805 & 474 & NI & 20 & 473(100), 269(26), 268(30) \\
\hline & acetylhexoside & 8.05 & $4 / 4$ & $\mathrm{NI}$ & 30 & $473(16), 269(34), 268(100)$ \\
\hline & & & & & 40 & $269(11), 268(100)$ \\
\hline & & & & & 10 & $269(100), 225(12), 151(10), 149(14), 117(15)$ \\
\hline & & & & & 20 & $269(100), 225(8), 151(12), 149(11), 117(13)$ \\
\hline \multirow[t]{3}{*}{29} & Apigenin & 8.81 & 270 & NI & 30 & $269(22), 225(6), 183(6), 181(5), 159(7), \begin{array}{c}151(26), \\
65(8)\end{array}$ \\
\hline & & & & & 40 & $121(6), 117(100), 107(10), 83(5), 65(14)$ \\
\hline & & & & & 10 & $301(9), 286(100), 258(64)$ \\
\hline \multirow{3}{*}{30} & $O$-Methyl-luteolin/ & & 300 & & 20 & $301(100), 286(58)$ \\
\hline & kaempferol & 9.13 & 300 & $\mathrm{PI}$ & 30 & $301(13), 286(100), 258(59)$ \\
\hline & & & & & 40 & $286(20), 258(100), 257(8), 229(17), 153(10)$ \\
\hline & $=$ negative ionization $\mathrm{mo}$ & & & & & \\
\hline
\end{tabular}

in solvent and not more than 0.146 min for the spiked matrix. During a calibration study (performed in a wide range of concentrations), a slight deviation from linearity was observed at higher concentrations. Therefore, the limit of linear range was determined as the highest standard concentration still resulting in satisfactory linearity $\left(r^{2}>0.98\right)$ of weighted calibration curve, for each compound. For limit of quantitation (LoQ) determination, solvent calibration standards were analyzed in 5 replicates each, and relative standard deviation of repeatability was plotted against concentration of each. A reliable quantitation limit (Table 2) was estimated at the lowest concentration still resulting in an acceptable repeatability $(<10 \%)$. Limit of detection (LoD) was estimated as the lowest concentration, resulting in a well-defined peak. The procedure was repeated in matrix (M. chamomilla flos, $100 \mu \mathrm{g} / \mathrm{mL}$ ), as well (Table 2).

A sample selected for investigation of method parameters in matrix (M. chamomilla flos, $100 \mu \mathrm{g} / \mathrm{mL}$ ) was spiked with the standard mixture and reanalyzed in 5 replicates, resulting in a satisfactory effect of only one peak being observable at specified retention time, for each compound. The peak width at half-minimum in spiked samples was in a range of $94-108 \%$ peak width in non-spiked samples, which is within the acceptable limits as defined by the European Community Council Directive 96/23/EC [37]. The retention times of all investigated compounds differed in spiked and non-spiked samples by $-0.5 \%$ to $0.5 \%$, which is also within the prescribed margin (5\%). Matrix effects were quantified using a post-extraction addition method. Solvent calibration (SC) and matrixmatched calibration (MMC) standards were prepared at all levels for all investigated compounds, using methanol-water mixture $(1: 1)$ and $M$. chamomilla extract $(100 \mu \mathrm{g} / \mathrm{mL}$ in methanol-water [1:1] mixture) as solvents, respectively. For each compound, signal suppression/enhancement (SSE) was calculated as a ratio of compound responses in matrix and in solvent, i.e., $\mathrm{SSE}=A_{\mathrm{MMC}}-A_{\mathrm{SC}}$. For most of the investigated compounds, SSE was close to 1 (with a deviation less than \pm 0.25 ) in a wide concentration range.

Identification and Quantification of Phenolic Compounds (LC-MS/MS Profiling). Extraction, separation, 
Table 4. Compounds detected in Tripleurospermum inodorum (L.) Sch. Bip. 1844 (M. inodora L.) samples 1-4 and M. chamomilla extract

\begin{tabular}{|c|c|c|c|c|c|c|c|}
\hline \multicolumn{2}{|c|}{ Peak No.Assignment } & \multicolumn{5}{|c|}{$\begin{array}{c}t_{\mathrm{R}}(\mathrm{min}) \text { Matricaria } \\
\text { inodora }\end{array}$} & \multirow[t]{2}{*}{ M.cham } \\
\hline & & & $\overline{1}$ & & 3 & 4 & \\
\hline 1 & Quinic acid & 1.04 & $+^{a}$ & + & + & + & + \\
\hline 2 & Chlorogenic acid & 1.53 & & & & + & + \\
\hline 3 & $1-/ 5-O-p$-Coumaroylquinic acid & 2.11 & + & + & + & + & $-b$ \\
\hline 4 & $O$-Hexosylferulic acid & 2.14 & - & - & - & - & + \\
\hline 5 & Myricetin-3-O-hexoside & 2.51 & - & - & - & - & + \\
\hline 6 & 1-/5-O-p-Coumaroylquinic acid & 2.85 & + & + & + & + & + \\
\hline 7 & Scopoletin & 3.18 & + & + & + & + & - \\
\hline 8 & 1,3-/3,5-O-Dicaffeoylquinic acid & 3.48 & + & + & + & + & + \\
\hline 9 & Luteolin- $O$-deoxyhexosylhexoside & e 3.81 & - & - & - & - & + \\
\hline 10 & Luteolin $-O$-hexoside & 3.92 & + & + & + & + & + \\
\hline 11 & Rutin & 4.04 & + & + & + & + & + \\
\hline 12 & Quercetin-3-O-hexoside & 4.13 & + & + & + & + & + \\
\hline 13 & Naringenin- $O$-hexoside & 4.18 & + & + & + & + & + \\
\hline 14 & Unidentified compound & 4.33 & + & + & + & + & - \\
\hline 15 & $\mathrm{x}, 4-O$-Dicaffeoylquinic acid & 4.55 & + & + & + & + & + \\
\hline 16 & Quercetin- $O$-Malonylhexoside & 4.74 & + & + & + & + & + \\
\hline 17 & Apigenin- $O$-hexoside & 4.99 & + & + & + & + & + \\
\hline 18 & Rhamnetin/Isorhamnetin-3-O-Hex & 5.16 & + & + & + & + & + \\
\hline 19 & Luteolin/Kaempferol-O-MalHex & 5.32 & + & + & + & + & + \\
\hline 20 & Rhamnetin/Isorhamnetin-3-O-Hex & 5.49 & + & + & + & + & + \\
\hline 21 & Rhamnetin/Isorhamnetin- $\mathrm{O}-\mathrm{AcHe}$ & $x 6.00$ & - & - & - & - & + \\
\hline 22 & Apigenin- $O$-acetylhexoside & 6.32 & + & + & + & + & - \\
\hline 23 & Unidentified compound & 6.55 & + & + & + & + & - \\
\hline 24 & Quercetin & 6.91 & + & + & + & + & + \\
\hline 25 & Naringenin & 7.30 & + & + & + & + & + \\
\hline 26 & Luteolin & 7.45 & + & + & + & + & + \\
\hline 27 & Unidentified compound & 7.70 & + & + & + & + & + \\
\hline 28 & Apigenin- $O$-acetylhexoside & 8.05 & + & + & + & + & + \\
\hline 29 & Apigenin & 8.81 & + & + & + & + & + \\
\hline 30 & $O$-Methyl-luteolin/kaempferol & 9.13 & + & + & + & + & - \\
\hline
\end{tabular}

identification and qualitative analysis of plant extracts is of huge importance for their quality control, as well as in identification of the flavor and health effects $[25,38]$. The identification of compounds in the $M$. inodora and $M$. chamomilla extracts based on the mass spectra obtained from qualitative LC-MS/MS analysis is shown in Table 3 and Table 4.

The compounds have been identified by comparing the mass-to-charge ratio $(\mathrm{m} / \mathrm{z})$ values (used to identify their molecular mass - hereby presented as monoisotopic mass, $M_{\mathrm{mi}}$ ) and the MS/MS spectra with the existing literature data [39-41]. As a result of the qualitative LC-MS/MS analysis, 19 various flavonoids and their derivatives have been identified: myricetin- $O$-hexoside ( $t_{\mathrm{R}} 2.51 \mathrm{~min} ; M_{\mathrm{mi}} 480 \mathrm{~g} / \mathrm{mol}$ ), luteolin- $O$-deoxyhexosylhexoside ( $\left.t_{\mathrm{R}} 3.81 \mathrm{~min} ; M_{\mathrm{mi}} 594 \mathrm{~g} / \mathrm{mol}\right)$, luteolin/ kaempferol- $O$-hexoside ( $\left.t_{\mathrm{R}} 3.92 \mathrm{~min} ; M_{\mathrm{mi}} 448 \mathrm{~g} / \mathrm{mol}\right)$, rutin $\left(t_{\mathrm{R}} 4.04 \mathrm{~min} ; M_{\mathrm{mi}} 610 \mathrm{~g} / \mathrm{mol}\right)$, quercetin-3-O-hexoside $\left(t_{\mathrm{R}}\right.$ $\left.4.13 \mathrm{~min} ; M_{\mathrm{mi}} 464 \mathrm{~g} / \mathrm{mol}\right)$, naringenin- $O$-hexoside $\left(t_{\mathrm{R}}\right.$ $\left.4.18 \mathrm{~min} ; M_{\mathrm{mi}} 434 \mathrm{~g} / \mathrm{mol}\right)$, quercetin- $O$-malonylhexoside $\left(t_{\mathrm{R}}\right.$ $\left.4.74 \mathrm{~min} ; M_{\mathrm{mi}} 550 \mathrm{~g} / \mathrm{mol}\right)$, apigenin- $O$-hexoside $\left(t_{\mathrm{R}} 4.99 \mathrm{~min}\right.$; $\left.M_{\mathrm{mi}} 432 \mathrm{~g} / \mathrm{mol}\right)$, rhamnetin/isorhamnetin-3-O-hexoside $\left(t_{\mathrm{R}}\right.$ $\left.5.16 \mathrm{~min} ; M_{\mathrm{mi}} 478 \mathrm{~g} / \mathrm{mol}\right)$, luteolin/kaempferol- $O$-malonylhexoside ( $\left.t_{\mathrm{R}} 5.32 \mathrm{~min} ; M_{\mathrm{mi}} 534 \mathrm{~g} / \mathrm{mol}\right)$, rhamnetin/isorhamnetin-3-O-hexoside ( $t_{\mathrm{R}} 5.49 \mathrm{~min} ; M_{\mathrm{mi}} 478 \mathrm{~g} / \mathrm{mol}$ ), rhamnetin/ isorhamnetin- $O$-acetylhexoside $\left(t_{\mathrm{R}} 6.00 \mathrm{~min} ; M_{\mathrm{mi}} 520 \mathrm{~g} / \mathrm{mol}\right)$, apigenin- $O$-acetylhexoside ( $\left.t_{\mathrm{R}} 6.32 \mathrm{~min} ; M_{\mathrm{mi}} 474 \mathrm{~g} / \mathrm{mol}\right)$, quercetin $\left(t_{\mathrm{R}} 6.91 \mathrm{~min} ; M_{\mathrm{mi}} 302 \mathrm{~g} / \mathrm{mol}\right)$, naringenin $\left(t_{\mathrm{R}}\right.$ $\left.7.30 \mathrm{~min} ; M_{\mathrm{mi}} 272 \mathrm{~g} / \mathrm{mol}\right)$, luteolin/kaempferol $\left(t_{\mathrm{R}} 7.45 \mathrm{~min}\right.$; $\left.M_{\mathrm{mi}} 286 \mathrm{~g} / \mathrm{mol}\right)$, apigenin- $O$-acetylhexoside $\left(t_{\mathrm{R}} 8.05 \mathrm{~min} ; M_{\mathrm{mi}}\right.$ $474 \mathrm{~g} / \mathrm{mol})$, apigenin $\left(t_{\mathrm{R}} 8.81 \mathrm{~min} ; M_{\mathrm{mi}} 270 \mathrm{~g} / \mathrm{mol}\right)$, and $O$-methyl-luteolin/kaempferol ( $\left.t_{\mathrm{R}} 9.13 \mathrm{~min} ; M_{\mathrm{mi}} 300 \mathrm{~g} / \mathrm{mol}\right)$.

For the detected hexosides, it was not possible to resolve the nature of hexose, due to the limitations of low resolution mass spectrometry. The qualitative analysis itself did not provide sufficient information in order to distinguish between luteolin and kaempferol in their methyl and malonyl hexoside form. However, the standard compounds used in the quantitative analysis have enabled the distinction of the two aglycons and their hexosides. Moreover, the overall high flavonoid content was confirmed by the quantitative analysis as well, with around $8-43 \mathrm{mg} / \mathrm{g}$ of targeted flavonoids in the examined extracts (Table 5).

The equivalently abundant phenolic compounds are quinic acid ( $\left.t_{\mathrm{R}} 1.04 \mathrm{~min} ; M_{\mathrm{mi}} 192 \mathrm{~g} / \mathrm{mol}\right)$, and its 5 identified derivatives: chlorogenic acid $\left(t_{\mathrm{R}} 1.53 \mathrm{~min} ; M_{\mathrm{mi}} 354 \mathrm{~g} / \mathrm{mol}\right), 1-/ 5-O-$ $p$-coumaroylquinic acid $\left(t_{\mathrm{R}} 2.11 \mathrm{~min} ; M_{\mathrm{mi}} 338 \mathrm{~g} / \mathrm{mol}\right), 1-/ 5-O-$ $p$-coumaroylquinic acid $\left(t_{\mathrm{R}} 2.85 \mathrm{~min} ; M_{\mathrm{mi}} 338 \mathrm{~g} / \mathrm{mol}\right), 1,3-/$ 3,5-di- $O$-caffeoylquinic acid $\left(t_{\mathrm{R}} 3.48 \mathrm{~min} ; M_{\mathrm{mi}} 516 \mathrm{~g} / \mathrm{mol}\right)$, and $x$,4-di- $O$-caffeoylquinic acid $\left(t_{\mathrm{R}} 4.55 \mathrm{~min} ; M_{\mathrm{mi}} 516 \mathrm{~g} /\right.$ mol). Interestingly, all of the quinic acid derivatives, including the quinic acid itself, are found in both $M$. inodora and chamomile extracts' samples. This is confirmed by quantitative analysis, where quinic acid and 5-O-caffeoylquinic acid are both very abundant in all examined samples (Table 6), comprising about $40-90 \%$ of targeted phenolic compounds detected in them, flavonoids excluded.

Low-resolution mass spectrometry did not enable the identification of the exact masses, making it a challenging task to identify some structure parts or entire compounds with certainty [42]. One example are the $2 O$-acetyl hexoside derivatives of apigenin (at $t_{\mathrm{R}}=6.32 \mathrm{~min}$ and $t_{\mathrm{R}}=8.05 \mathrm{~min}$, respectively), both with $M_{\mathrm{mi}}=474 \mathrm{~g} / \mathrm{mol}$, identified based on their retention times, as well as the $\mathrm{MS}^{1}$ and $\mathrm{MS}^{2}$ spectra. However, it was not possible to determine the nature or position of the sugar moiety, as mentioned earlier. Nevertheless, the compound with a retention time of $8.05 \mathrm{~min}$ is detected in both chamomile and $M$. inodora extracts, while the one with $t_{\mathrm{R}}=6.32 \mathrm{~min}$ is found only in inodorous chamomile samples (Table 4). The literature data suggests that Api-7-(6"-acetylGlc) and Api-7-(4"-acetyl-Glc), compounds with antiphlogistic and spasmolytic properties [43], were both detected in white florets of chamomile (Chamomilla recutita Rauschert) [42]. One of them, Api-7-(6"-acetyl-Glc), was also previously reported as one of the main acylated derivatives of apigenin [44], and still it is rather difficult to determine if it could be identified as compound 28 hereby (Table 4).

Similarly, there are $2 p$-coumaroylquinic acids, at $t_{\mathrm{R}}=$ $2.11 \mathrm{~min}$ and $2.85 \mathrm{~min}$, respectively, both with $M_{\mathrm{mi}}=338 \mathrm{~g} /$ mol, and with the two possible positions of coumaroyl group identified as $1-O$ - or $5-O-$, based on their specific MS/MS spectra [45-47]. The 1-O-p-coumaroylquinic acid usually occurs together in an extract with 5-O-coumaroylquinic acid [48], although the 5-O-coumaroylquinic acid is generally more commonly occurring in plants [46-49], being labeled as an antioxidative agent [50]. Nevertheless, it is not possible to identify either of them with certainty, based solely on their retention time and low-resolution mass spectra. The compound at a retention time of $3.48 \mathrm{~min}$ was identified as either 1,3-Odicaffeoylquinic acid (i.e., cynarin) or 3,5-O-dicaffeoylquinic acid. At $4.55 \mathrm{~min}$, a compound is also designated as an $O$ dicaffeoylquinic acid, yet with at least one of the caffeoyl acid moieties at position 4. This suggestion is supported by the characteristic MS spectra [51, 52]. 1,3-O-Dicaffeoylquinic acid (i.e., cynarin) exhibits in vitro antimicrobial abilities $[52,53]$ and has a potent anti-ulcer and gastric-protective activity [50] and cholesterol-lowering effect $[52,53]$. Cynarin is expected to have much shorter retention time than 3,5-Odicaffeoylquinic acid [52] and 1,5-dicaffeoylquinic acid $[52,54]$ on a reversed-phased $\mathrm{C}_{18}$ column. Moreover, it would have eluated notably earlier compared to 3,4-O-dicaffeoylquinic acid on the same column, while 4,5-O-dicaffeoylquinic 
Table 5. Concentrations of flavonoid compounds in Tripleurospermum inodorum (L.) Sch. Bip. 1844 (M. inodora L.) samples $1-4$ and M. chamomilla extract (all given in $\mu \mathrm{g}$ per $\mathrm{g}$ of dry extract)

\begin{tabular}{|c|c|c|c|c|c|c|}
\hline Class & Compound & M.ino_1 & M.ino_2 & M.ino_3 & M.ino_4 & M.chamomilla \\
\hline \multirow{5}{*}{ Flavones } & Apigenin & $1582 \pm 111$ & $2401 \pm 168$ & $13,837 \pm 969$ & $443 \pm 31$ & $658 \pm 46$ \\
\hline & Baicalein & $69.6 \pm 2.1$ & $102 \pm 3.1$ & $144 \pm 4.3$ & $<40$ & $<40$ \\
\hline & Luteolin & $1988 \pm 99$ & $1618 \pm 81$ & $6859 \pm 343$ & $2394 \pm 120$ & $90.5 \pm 4.5$ \\
\hline & Chrysin & $<0.12$ & $2.69 \pm 0.13$ & $7.91 \pm 0.40$ & $<0.12$ & $<0.12$ \\
\hline & Chrysoeriol & $287 \pm 8.6$ & $386 \pm 12$ & $1038 \pm 31$ & $260 \pm 7.8$ & $52.4 \pm 1.6$ \\
\hline \multirow{5}{*}{ Flavone glycosides } & Vitexin & $<0.4$ & $0.517 \pm 0.03$ & $1.13 \pm 0.06$ & $0.353 \pm 0.02$ & $1.01 \pm 0.05$ \\
\hline & Apigenin-7-O-glucoside & $3639 \pm 182$ & $422 \pm 21$ & $17,244 \pm 862$ & $3025 \pm 151$ & $20,301 \pm 1015$ \\
\hline & Luteolin-7- $O$-glucoside & $3029 \pm 91$ & $1213 \pm 36$ & $1537 \pm 46$ & $4221 \pm 127$ & $1222 \pm 37$ \\
\hline & Apiin & $24.8 \pm 1.2$ & $29.6 \pm 1.5$ & $23.9 \pm 1.2$ & $20.9 \pm 1.0$ & $0.765 \pm 0.04$ \\
\hline & Kaempferol & $32.7 \pm 2.3$ & $17.3 \pm 1.2$ & $92.1 \pm 6.4$ & $30.9 \pm 2.2$ & $16.0 \pm 1.1$ \\
\hline \multirow{3}{*}{ Flavonols } & Quercetin & $30.2 \pm 0.90$ & $26.3 \pm 0.79$ & $135 \pm 4.1$ & $84.1 \pm 2.5$ & $26.4 \pm 0.79$ \\
\hline & Isorhamnetin & $155 \pm 9.3$ & $152 \pm 9.1$ & $552 \pm 33$ & $274 \pm 16$ & $60.5 \pm 3.6$ \\
\hline & Morin & $45.2 \pm 3.6$ & $59.6 \pm 4.8$ & $145 \pm 12$ & $42.7 \pm 3.4$ & $19.6 \pm 1.6$ \\
\hline \multirow{3}{*}{ Flavonol glysocides } & Kaempferol-3-O-glucoside & $9.25 \pm 0.37$ & $8.53 \pm 0.34$ & $20.6 \pm 0.82$ & $25.9 \pm 1.0$ & $34.5 \pm 1.4$ \\
\hline & Hyperoside & $<0.2$ & $<0.2$ & $15.5 \pm 0.93$ & $<0.2$ & $<0.2$ \\
\hline & Quercetin-3-O-glucoside & $19.2 \pm 0.57$ & $28.5 \pm 0.86$ & $53.2 \pm 1.6$ & $146 \pm 4.4$ & $132 \pm 3.9$ \\
\hline \multirow{3}{*}{ Flavanones } & Naringenin & $186 \pm 13$ & $1008 \pm 71$ & $350 \pm 25$ & $55.4 \pm 3.9$ & $6.59 \pm 0.46$ \\
\hline & Pinocembrin & $<0.06$ & $2.99 \pm 0.09$ & $<0.06$ & $<0.06$ & $<0.06$ \\
\hline & Pinostrobin & $<0.06$ & $<0.06$ & $<0.06$ & $1.50 \pm 0.03$ & $1.71 \pm 0.03$ \\
\hline Flavanone glycosides & Naringin & $14.4 \pm 0.57$ & $13.6 \pm 0.54$ & $19.7 \pm 0.79$ & $8.26 \pm 0.33$ & $1.89 \pm 0.08$ \\
\hline \multirow{2}{*}{ Flavanols } & Catechin & $<0.4$ & $<0.4$ & $<0.4$ & $<0.4$ & $5.90 \pm 0.06$ \\
\hline & Epicatechin & $<1.6$ & $<1.6$ & $<1.6$ & $<1.6$ & $5.43 \pm 0.05$ \\
\hline Biflavonoids & Amentoflavone & $<0.08$ & $<0.08$ & $<0.08$ & $0.243 \pm 0.01$ & $0.332 \pm 0.01$ \\
\hline \multirow{3}{*}{ Isoflavonoids } & Genistein & $<2$ & $<2$ & $<2$ & $<2$ & $2.88 \pm 0.20$ \\
\hline & Formononetin & $0.339 \pm 0.01$ & $0.286 \pm 0.01$ & $0.273 \pm 0.01$ & $0.378 \pm 0.01$ & $0.299 \pm 0.01$ \\
\hline & TOTAL & $11,475 \pm 533$ & $7953 \pm 421$ & $43,103 \pm 2362$ & $11,366 \pm 478$ & $22,730 \pm 1120$ \\
\hline
\end{tabular}

acid, 3,5-O-dicaffeoylquinic acid, and 1,4-O-dicaffeoylquinic acid, were all eluted significantly later [52, 54]. This could suggest that the compound labeled as 8 could, in fact, be cynarin, while compound 15 is possible to be 3,4-O-dicaffeoylquinic acid, since eluting after compound 8 but not yet with very elongated retention time, which would otherwise be expected from the 4,5- or 1,4-O-dicaffeoylquinic derivative [52].

As apparent from Table 4, most of the detected compounds are present in all the examined samples of both $M$. inodora and chamomile extracts. This makes it a challenging task to identify possible specific taxonomic or adulteration markers in them. The concentrations of apigenin are similar in both $M$. inodora and chamomile extracts [4, 27] (Table 5), interestingly even slightly higher in the examined $M$. inodora extracts $(0.4-13.8 \mathrm{mg} / \mathrm{g})$ than in the chamomile sample $(0.7 \mathrm{mg} / \mathrm{g})$. On the other hand, although present in relatively high levels in $M$. inodora extracts $(0.4-17.2 \mathrm{mg} / \mathrm{g})$, apigenin-7- $O$-glucoside, commonly regarded as an active marker in chamomile flowers $[4,21,22]$, is indeed more abundant in the chamomile extract $(20.3 \mathrm{mg} / \mathrm{g})[9,10]$. Also, according to the qualitative analysis, compounds such as $O$-hexosyl ferulic acid, myricetin-3-Ohexoside, luteolin- $O$-deoxyhexosylhexoside, and rhamnetin/ isorhamnetin- $O$-acetylhexoside are only detected in the $M$. chamomila sample. On the other hand, 1-/5-O-p-coumaroylquinic acid, scopoletin, apigenin- $O$-acetylhexoside (at $t_{\mathrm{R}}=$ $6.32 \mathrm{~min}$ ), and $O$-methyl-luteolin/kaempferol are present just in inodorous chamomile extracts. The abovementioned compounds could, therefore, be considered as chemotaxonomic markers in the case of potential chamomile adulteration. Moreover, the quantitative analysis has pointed out that luteolin is present in higher concentrations in M. inodora extracts,

Table 6. Concentrations of phenolic compounds in Tripleurospermum inodorum (L.) Sch. Bip. 1844 (M. inodora L.) samples $1-4$ and M. chamomilla extract (all given in $\mu \mathrm{g}$ per $\mathrm{g}$ of dry extract)

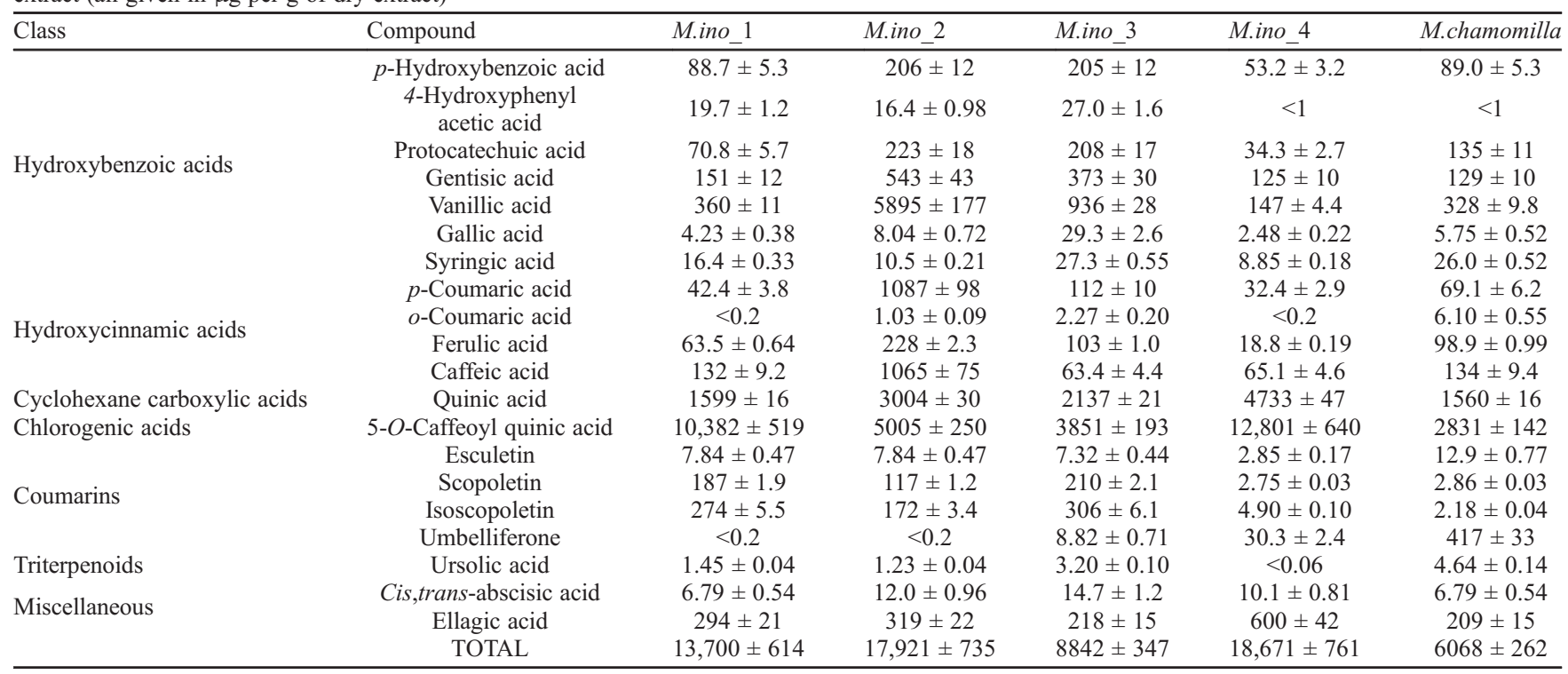


when compared to chamomile flower heads' extract (1.62-6.86 mg/g vs. $90.5 \mu \mathrm{g} / \mathrm{g}$, respectively), as seen in the qualitative analysis, as well, where peak of luteolin is much lower in the chamomile sample. Thus, it could not be considered as a taxonomic marker, but its unusually high concentration could possibly indicate the absence or smaller share of chamomile in an adulterated sample $[55,56]$.

As seen from both Table 5 and Table 6, all examined samples have rather high combined phenolic and flavonoid content $(25.2 \mathrm{mg} / \mathrm{g}, 25.9 \mathrm{mg} / \mathrm{g}, 51.9 \mathrm{mg} / \mathrm{g}$, and $30.0 \mathrm{mg} / \mathrm{g}$ in the M. inodora 1-4 samples, respectively, and $28.8 \mathrm{mg} / \mathrm{g}$ in the $M$. chamomilla extract). Among them, sample 3 of $M$. inodora has the highest flavonoid level $(43.1 \mathrm{mg} / \mathrm{g})$, whereas the other $3 M$. inodora samples have flavonoid content between 7.95 and $11.5 \mathrm{mg} / \mathrm{g}$. In the M. chamomilla extract, the flavonoid content was relatively high, as well, with $22.7 \mathrm{mg} / \mathrm{g}$ of the detected flavonoids. Concentrations of the rest of quantified phenolics in samples 1,2 , and 4 of $M$. inodora were higher $-13.7 \mathrm{mg} / \mathrm{g}, 17.9 \mathrm{mg} / \mathrm{g}$, and $18.7 \mathrm{mg} / \mathrm{g}$, respectively. In sample 3 of $M$. inodora and in the $M$. chamomilla extract, flavonoids were the dominant compounds, with $8.8 \mathrm{mg} / \mathrm{g}$ and $6.1 \mathrm{mg} / \mathrm{g}$ of residual phenolic content, respectively.

Apigenin, apigenin-7-O-glucoside, luteolin, luteolin-7-Oglucoside, quinic acid, and 5-O-caffeoyl quinic acid, i.e., chlorogenic acid, alongside caffeic acid, are the most abundant in samples of both inodorous and common chamomile, as expected from the studies published earlier [2, 29, 57]. Umbelliferone, as well as several other coumarins including herniarin, were also previously reported in the extracts of chamomile [58, 59]. 5-O-Caffeoyl quinic acid is one of the main phenolic compounds in both chamomile [2, 4, 24, 29, 60] and the scentless mayweed. It is a known antioxidant agent [61], with somewhat lower tumor-growth inhibitory activity [2]. High yield of caffeic acid was also reported before in chamomile samples [20, 24, 29]. In this study, although present in all examined samples, caffeic acid is found not to be one of the major compounds, with a concentration of 63.4-1065 $\mu \mathrm{g} / \mathrm{g}$ (Table 6).

Apigenin-7-O-glucoside is considered as the major constituent of chamomile [4, 21, 22, 57], and one of the compounds responsible for its anti-inflammatory activity [11,62]. Apigenin is also typical for chamomile [27]. It is a well-known anti-inflammatory [57], antioxidant [62], and cancer-preventive agent [63-65]. Luteolin, highly abundant in chamomile, also contributes to its high anti-inflammatory $[2,66]$, antimutagenic, antitumorigenic, and antioxidant properties [67]. Luteolin-7-O-glucoside is also one of the abundant compounds in chamomile $[2,4,29]$, equally abundant in the examined samples (Table 5). The biological activities of luteolin-7-O-glucoside comprise mostly of its high antioxidant activity [68]. It can also act as a gastroprotective agent, due to the antisecretory, anti-inflammatory, and antiapoptotic activity $[69,70]$. In this manner, chamomile tea adulteration with the $M$. inodora plants high in apigenin and luteolin content seems to even be able to contribute to its potentially promising benefits, i.e., health-promoting properties $[64,71]$.

\section{Conclusion}

A new HPLC-MS/MS method has been developed for the quantification of 25 phenolic compounds commonly occurring in plants. The established method was validated and applied in the first detailed chemical profile, i.e., phenolic fingerprinting of methanolic extracts of scentless chamomile (T. inodorum (L.) Sch. Bip. 1844 (M. inodora L.)).

Acknowledgements. This work was financially supported by a research grant from the Ministry of Education, Science and Technological Development of the Republic of Serbia (Grant No. 172058).

\section{References}

1. Ignat, I.; Volf, I.; Popa, V. I. Food Chem. 2011, 126, 1821-1835.

2. Guimaraes, R.; Calhelha, R. C.; Froufe, H. J. C.; Abreu, R. M.; Carvalho, A. M.; Joao, M.; Queiroz, R. P.; Ferreira, I. C. F. R. Food Funct. 2016, 7, 79-83.

3. Harbourne, N.; Jacquier, J. C.; O'Riordan, D. Food Chem. 2009, 115 $15-19$.

4. Avula, B.; Wang, Y. H.; Wang, M.; Avonto, C.; Zhao, J.; Smillie, T. J.; Rua, D.; Khan, I. A. J. Pharmaceut. Biomed. 2014, 88, 278-288.

5. Balasundram, N.; Sundram, K.; Samman, S. Food Chem. 2006, 99, 191-203.

6. Cemek, M.; Yilmaz, E.; Buyukokuroglu, M. E. Pharm. Biol. 2010, 48, 757-763.

7. Applequist, W. L. Taxon. 2002, 51, 757-761.

8. Hernandez-Ceruelos, A.; Madrigal-Santillan, E.; Morales-Gonzales, J. A.; Chamorro-Cevallos, G.; Cassani-Galindo, M.; Madrigal-Bujaidar, E. Int J. Mol. Sci. 2010, 11, 3793-3802.

9. Srivastava, J. K.; Pandey, M.; Gupta, S. Life Sci. 2009, 85, 663-669.

10. Fonseca, F. N.; Tavares, M. F. M. Phytochem. Anal. 2004, 15, 65-70.

11. Petronilho, S.; Maraschin, M.; Coimbra, M. A.; Rocha, S. M. Ind.

Crop. Prod. 2012, 40, 1-12.

12. Bär, B.; Schultze, W. Planta Med. 1996, 62, 332-335.

13. Woo, S. L.; Thomas, A. G.; Peschken, D. P.; Bowes, G. G.; Douglas,

D. W.; Harms, V. L.; McClay, A. S. Can. J. Plant Sci. 1991, 71, 1101-1119.

14. Furuset, K. Blyttia. 2013, 71, 169-174.

15. Hansen, H. V.; Christensen, K. I. Taxon. 2009, 58, 261-264.

16. Ali, A.; Streibig, J. C.; Christensen, S.; Andreasen, C. Weed Res. 2015, $55,26-33$.

17. Salonen, J.; Laitinen, P.; Saastamoinen, M.; Salopelto, J. Agr. Food Sci. 2011, 20, 262-268.

18. Mahernia, S.; Bagherzadeh, K.; Mojab, F.; Amanlou, M. Iran. J. Pharm. Res. 2015, 14, 943-947.

19. Hartl, A.; van Bommel, M. R.; Joosten, I.; Hoffman-de Keijzer, R.; Grömer, K.; Rösel-Mautendorfer, H.; Reschreiter, H. J. Archaeol. Sci. 2015, 2 , 569-595.

20. Viapiana, A.; Struck-Lewicka, W.; Konieczynski, P.; Wesolowski, M.; Kaliszan, R. Front Plant. Sci. 2016, 1561.

21. Guzelmeric, E.; Vovk, I.; Yesilada, E. J. Pharmaceut. Biomed. 2015 $107,108-118$.

22. Guzelmeric, E.; Ristivojević, P.; Vovk, I.; Milojković-Opsenica, D.; Yesilada, E. J. Pharmaceut. Biomed. 2017, 132, 35-45.

23. Novakova, L.; Spačil, Z.; Seifrtova, M.; Opletal, L.; Solich, P. Talanta. 2010, 80, 1970-1979.

24. Novakova, L.; Vildova, A.; Mateus, J. P.; Goncalves, T.; Solich, P. Talanta. 2010, 82, 1271-1280.

25. Ji, M.; Li, C.; Li, Q. J. Chromatogr. A. 2015, 1414, 138-146.

26. Lai, J. P.; Lim, Y. H.; Su, J.; Shen, H. M.; Ong, C. N. J. Chromatogr. B. 2007, 848, 215-225.

27. Agatonovic-Kustrin, S.; Ortakand, D. B.; Morton, D. W.; Yusof, A. P.

J. Chromatogr. A. 2015, 1385, 103-110.

28. Morlock, G. E.; Ristivojević, P.; Chernetsova, E. S. J. Chomatogr. A. 2014, 1328, 104-112.

29. Fonseca, F. N.; Tavares, M. F. M.; Horvath, C. J. Chromatogr. A. 2007, $1154,390-399$

30. Koch, W.; Kukula-Koch, W.; Marzec, Z.; Kasparek, E.; WyszogrodzkaKoma, L.; Szwerc, W.; Asakawa, Y. Int. J. Mol. Sci. 2017, 18, 452.

31. Koch, W.; Kukula-Koch, W.; Komsta, L. Molecules 2018, 23, 513.

32. Nađpal, J.; Lesjak, M.; Šibul, F.; Anačkov, G. T.; Četojević-Simin, D. Mimica-Dukić, N.; Beara, I. Food Chem. 2016, 192, 907-914.

33. Orčić, D.; Francišković, M.; Bekvalac, K.; Svirčev, E.; Beara, I.; Lesjak, M. Food Chem. 2014, 143, 48-53.

34. Šibul, F.; Orčić, D.; Vasić, M.; Anačkov, G.; Nađpal, J.; Savić, A.; Mimica-Dukić, N. Ind. Crop. Prod. 2016, 83, 641-653.

35. Zöllner, T.; Schwarz, M. Rev. Bras. Farmacogn. 2013, 23, 1-21.

36. Šibul, F. S.; Orčić, D. Z.; Svirčev, E.; Mimica-Dukić, N. M. Hem. Ind. 2016, 70, 473-483.

37. Byrne, D. Official J. Eur. Communities 2002, L221, 8-36.

38. Malec, P. A.; Oteri, M.; Inferrera, V.; Cacciola, F.; Mondello, L.; Kennedy, R. T. J. Chomatogr. A. 2017, 1523, 248-256.

39. Dou, J.; Lee, V. S. Y.; Tzen, J. T. C.; Lee, M. R. J. Agric. Food Chem 2007, 55, 7462-7468.

40. Yawadio, R.; Tanimori, S.; Morita, N. Food Chem. 2007, 101, $1616-1625$.

41. Wyrepkowski, C. C.; , Costa, D. L. M. G.da; Sinhorin, A. P.; Vilegas, W.; , Grandis, R. A.de; Resende, F. A.; Varanda, E. A.; , Santos, L. C.dos Molecules. 2014, 19, 16039-16057.

42. Švehlikova, V; Bennett, R. N.; Mellon, F. A.; Needs, P. W; Piacente, S.; Kroon, P. A.; Bao, Y. Phytochem. 2004, 65, 2323-2332.

43. Achterrath-Tuckermann, U.; Kunde, R.; Flaskamp, E.; Isaac, O.; Thiemer, K. Planta Med. 1980, 39, 38-50.

44. Redaelli, C.; Formentini, L.; Santaniello, E. Phytochem. 1982, 21, $1828-1830$.

45. Clifford, M. N.; Johnston, K. L.; Knight, S.; Kuhnert, N. J. Agric. Food Chem. 2003, 51, 2900-2911.

46. Clifford, M. N.; Marks, S.; Knight, S.; Kuhnert, N. J. Agr. Food Chem. 2006, 54, 4095-4101. 
47. Clifford, M. N.; Zheng, W.; Kuhnert, N. Phytochem. Anal. 2006, 17, 384-393.

48. Sun, Y.; Li, H.; Hu, J.; Li, J.; Fan, Y. W.; Liu, X. R.; Deng, Z. Y. J. Agr. Food Chem. 2013, 61, 10507-10515.

49. Ossipov, V.; Nurmi, K.; Loponen, J.; Haukioja, E.; Pihlaja, K. J. Chromatogr. A. 1996, 721, 59-68.

50. Podio, N. S.; Lopez-Froilan, R.; Ramirez-Moreno, E.; Bertrand, L.; Baroni, M. V.; Perez-Rodriguez, M. L.; Sanchez-Mata, M. C.; Wunderlin, D. A. J. Agr. Food Chem. 2015, 63, 9572-9582.

51. Carlotto, J.; da Silva, L. M.; Dartora, N.; Maria-Ferreira, D.; Sabry, D. A.; Filho, A. P. S.; Werner, M. F. P.; Sassaki, G. L.; Gorin, P. A. J.; Iacomini, M.; Cipriani, T. R.; de Souza, L. M. Talanta. 2015, $135,50-57$.

52. Gouveia, S. C.; Castilho, P. C. Food Res. Int. 2012, 48, 712-724.

53. Lattanzio, V.; Kroon, P. A.; Linsalata, V.; Cardinali, A. J. Funct. Food. 2009, 1, 131-144.

54. Parejo, I.; Viladomat, F.; Bastida, J.; Codina, C. Anal. Chim. Acta. 2004, 512, 271-280.

55. Gürdal, B.; Kültür, S. J. Ethnopharmacol. 2013, 146, 113-126.

56. Kaval, I.; Behcet, L.; Cakilcioglu, U. J. Ethnopharmacol. 2014, 155 , $171-184$.

57. Srivastava, J. K.; Gupta, S. Mol. Cell. Pharmacol. 2009, 1, 138-147.

58. Petrulova-Poracka, V.; Repčak, M.; Vilkova, M.; Imrich, J. Food Chem. 2013, 14, 54-59.
59. Sagi, S.; Avula, B.; Wang, Y.-H.; Zhao, J.; Khan, I. A. J. Sep. Sci. 2014, 37, 2797-2804.

60. Kovačik, J.; Klejdus, B. Food Chem. 2014, 142, 334-341.

61. Kim, H. J.; Lee, Y. S. Plant Med. 2005, 71, 871-876.

62. O'Prey, J.; Brown, J.; Fleming, J.; Harrison, P. R. Biochem. Pharmacol. 2003, 66, 2075-2088.

63. Shankar, E.; Goel, A.; Gupta, K.; Gupta, S. Curr. Pharmacol. Rep. 2017, 3, 423-446.

64. Madunić, J.; Madunić, I. V.; Gajski, G.; Popić, J.; Garaj-Vrhovac, V. Cancer Lett. 2018, 413, 11-22.

65. Yin, F.; Giuliano, A. E.; Van Herle, A. J. Anticancer Res. 1999, 19, 4297-4303.

66. Kim, H. J.; Lee, W.; Yun, J. M. Phytother. Res. 2014, 28, 1383-1391.

67. Kim, H. Y.; Jung, S. K.; Buyn, S.; Son, J. E.; Oh, M. H.; Lee, J.; Kang, M. J.; Heo, Y. S.; Lee, K. W.; Lee, H. J. Phytother. Res. 2013, 27, 1481-1488. 68. Abeywickrama, G.; Debnath, S. C.; Ambigaipalan, P.; Shahidi, F. J. Agr. Food Chem. 2016, 64, 9342-9351.

69. Antonisamy, P.; Subash-Babu, P.; Albert-Baskar, A.; Alshatwi, A. A.; Aravinthan, A.; Ignacimuthu, S.; Choi, K. C.; Lee, S. C.; Kim, J. H. J. Funct. Food. 2016, 25, 302-313.

70. Han, Y.; Zhou, M.; Wang, L.; Ying, X.; Peng, J.; Jiang, M.; Bai, G.; Luo, G. J. Ethnopharmacol. 2015, 174, 387-395.

71. Yin, F.; Giuliano, A. E.; Law, R. E.; Van Herle, A. J. Anticancer Res. 2001, 21, 413-420. 